\title{
Faktor yang Mempengaruhi Akseptor dalam Memilih Alat Kontrasepsi Suntik
}

\author{
Fenti Hasnani \\ Jurusan Keperawatan Poltekkes Kemenkes Jakarta I \\ email: fenti112@hotmail.com
}

Submitted: 15-04-2019, Revised: 21-05-2019, Revised: 24-06-2019 Accepted: 24-06-2019

\begin{abstract}
Abstrak
Kontrasepsi hormonal jenis KB suntik di Indonesia semakin banyak dipakai karena kerjanya yang efektif, pemakaian praktis, harganya relatif murah dan aman. Cara ini mulai disukai masyarakat dan diperkirakan setengah juta pasangan memakai kontrasepsi suntikan untuk mencegah kehamilan. Tujuan penelitian: Penelitian ini bertujuan untuk mengetahui faktor-faktor yang memengaruhi akseptor KB dalam memilih alat kontrasepsi KB Suntik. Metode: Penelitian dilakukan di Puskesmas Langsa Lama Kota Langsa tahun 2017. Populasi dalam penelitian ini adalah seluruh Wanita Usia Subur yang berkunjung ke Puskesmas Langsa Lama. Tehnik pengambilan sampel dalam penelitian ini adalah dilakukan secara accidental sampling yaitu setiap responden yang berkunjung ke Puskesmas Langsa Lama, diberikan kuesioner satu persatu sampai terkumpul 62 pasien. Uji validitas dan reabilitas kuisioner dilakukan terhadap 30 reponden pada Januari 2017 di Puskesmas yang sama. Penelitian ini bersifat analitik dengan desain penelitian crosssectional dan tes chi square untuk mengevaluasi kemaknaan hubungan antara faktor. Hasil: Hasil penelitian didapat faktor pengetahuan $(\mathrm{p}$-value $=0,004)$ dan sosial ekonomi $\quad(p$-value $<0,001) \quad$ memengaruhi perilaku mayoritas akseptor dalam memilih alat kontrasepsi. Sedangkan tingkat pendidikan tidak memiliki pengaruh dalam pemilihan kontrasepsi. Kesimpulan: Dari hasil penelitian ini sangat diharapkan agar petugas kesehatan dapat lebih meningkatkan konseling kontrasepsi sebelum pemberian kontrasepsi kepada Akseptor KB.
\end{abstract}

Kata kunci: Akseptor, kontrasepsi, KB Suntik

\section{ABSTRACT}

The injection method of hormonal contraception in Indonesia is increasingly used because of its effective work, practical use, the price is relatively cheap and safe. This method began to be liked by the public and an estimated half a million couples used contraceptive injections to prevent pregnancy. Purpose of the study: This study aims to determine the factors that influence family planning acceptors in choosing family planning contraceptives using the injection method. Methods: The study was conducted in Langsa Health Center, Langsa City in 2017. The population in this study were all fertile women who visited Langsa Lama Health Center. The sampling technique was carried out by accidental sampling, namely each respondent who visited the Langsa Lama Health Center, given a questionnaire one by one until there were 62 patients collected. The validity and reliability test of the questionnaire was conducted on 30 respondents in January 2017 at the same Puskesmas. This study was analytical with a cross-sectional study design and chi square test to evaluate the significance of the relationship between factors. Results: The results of the study obtained knowledge factors ( $p$-value $=0.004)$ and socio-economic ( $p$-value <0.001) affecting the behavior of the majority of acceptors in choosing contraception. While the level of education does not have an influence in the selection of contraception. Conclusion: From the results of this study it is expected that health workers can further improve contraceptive counseling before giving contraception to family planning acceptors.

Keyword: Acceptors, contraception, injection contraception.

Pendahuluan
Perkembangan
program


berkualitas. Saat ini angka kelahiran rata-rata (Total Fertility Rate/TFR) pasangan suami istri masih 2,6. Sedangkan target yang harus dipenuhi 2,1 TFR dari yang telah ditetapkan tahun 2015. Hal ini akan terus digencarkan hingga tahun 2025 (CNN Indonesia, 2017).

Hasil penelitian Karuniawati (2005) menemukan mayoritas akseptor yang memilih alat kontrasepsi suntik adalah yang berpengetahuan cukup yaitu sebanyak 38 responden (61,3\%), mayoritas akseptor berpendidikan menengah yaitu sebanyak 31 responden $(50,0 \%)$ dan mayoritas akseptor dengan tingkat sosial ekonomi tinggi yaitu sebanyak 34 responden $(54,8 \%)$. Ada hubungan antara pemilihan kontrasepsi terhadap pengetahuan ibu dan sosial ekonomi.

Data dari Dinas Kesehatan Kota Langsa persentase peserta KB baru tahun 2012, dari total jumlah pasangan usia subur (PUS) yaitu 25.876 pasangan yang merupakan peserta $\mathrm{KB}$ baru adalah sebanyak 2.962 konseptor dengan berbagai alat kontrasepsi yang digunakan (Dinas Kesehatan Kota Langsa, 2016). Cakupan secara lengkap menurut Dinas Kesehatan Kota Langsa tahun 2012 dapat dilihat dari proporsi peserta KB baru berdasarkan alat kontrasepsi, menunjukkan jumlah pengguna KB terbanyak dan sering digunakan adalah suntikan dan pil masingmasing 8.182 konseptor $(31,6 \%)$ dan 8.370 konseptor $(32,3 \%)$, sedangkan untuk jenis kontrasepsi lainnya seperti Implant 185 (0,7\%), IUD 1149 (4,4\%), MOP/MOW 83 $(0,3 \%)$, Kondom 1547 (5,9\%), dan lainnya (Dinas Kesehatan Kota Langsa, 2016).

Data Pasangan Usia Subur (PUS) berjumlah 3.840 jiwa, jumlah peserta KB Baru sebanyak 990 (51,8\%) dan KB Aktif 2743 (71,4\%). Dari semua akseptor KB di Puskesmas Langsa Lama diketahui akseptor pil sebanyak 1.203 orang (43,9\%), suntik 1.392 orang $(50,7 \%)$, IUD 24 orang $(0,9 \%)$, MOP/MOW 8 orang $(0,3 \%)$, implant 5 orang $(0,2 \%)$, kondom 71 orang $(2,6 \%)$, obat vagina 15 orang $(0,5 \%)$, lainnya 25 orang $(0,9 \%)$. Dari data tersebut menunjukkan ada peningkatan jumlah peserta KB baru sebanyak 990 PUS (51,8\%). (Dinas Kesehatan Kota Langsa, 2016).

Secara umum penelitian bertujuan untuk mengetahui faktor-faktor yang memengaruhi akseptor KB dalam memilih alat kontrasepsi KB suntik. Sedangkan tujuan khusus adalah untuk mengetahui faktor-faktor yang memengaruhi akseptor KB dalam memilih alat kontrasepsi KB suntik ditinjau dari pendidikan dan pengetahuan serta sosial ekonomi akseptor KB di Puskesmas Langsa Lama Kota Langsa.

\section{Metode}

Penelitian ini bersifat analitik untuk mengetahui faktor-faktor yang memengaruhi akseptor KB dalam memilih alat kontrasepsi KB suntik di Puskesmas Langsa Lama Kota Langsa, dengan desain penelitian crosssectional (sekat silang).

Penelitian dilakukan di Puskesmas Langsa Lama pada tahun 2017. Populasi dalam penelitian ini adalah seluruh PUS (Pasangan Usia Subur) yang berkunjung ke Puskesmas Langsa Lama. Tehnik pengambilan sampel adalah accidental sampling yaitu PUS (Pasangan Usia Subur) yang berkunjung ke Puskesmas Langsa Lama, didapatkan hasil 62 responden. Kriteria inklusi adalah karakteristik umum subjek penelitian dari suatu populasi target yang terjangkau yang akan diteliti yaitu Pasangan Usia Subur (PUS), PUS yang berkunjung ke Puskesmas Langsa Lama dan PUS yang bersedia menjadi responden. Uji validitas dan reabilitas kuisioner dilakukan terhadap 30 reponden pada Januari 2017 di Puskesmas yang sama. Penelitian ini bersifat analitik dengan desain penelitian crosssectional dan tes chi square untuk mengevaluasi kemaknaan hubungan antara faktor.

Variabel penggunaan alat kontrasepsi suntik adalah alat kontrasepsi yang diberikan melalui penyuntikan, dengan jawaban ya atau tidak. Variabel independen terdiri dari pendidikan, pengetahuan dan sosial ekonomi. Pendidikan adalah tingkat pedidikan tertinggi yang pernah ditempuh ibu dan memiliki ijizah. Pengukuran variable pendidikan dan pengetahuan ibu berdasarkan pernyataan yang dikemukakan oleh Notoatmodjo (2007). Variabel pendidikan diukur dengan kuesioner dengan skala ordinal dan jawaban terdiri dari pendidikan tinggi (diploma/sarjana), pendidikan menengah (tingkat SMU sederajat) dan pendidikan dasar (SMP, SD sederajat). sedangkan pengetahuan ibu adalah pemahaman ibu tentang kontrasepsi, yang diukur dengan skala ordinal dengan hasil 
jawaban baik jika responden mampu menjawab benar $\geq 20$ pertanyaan, katagori cukup jika responden mampu menjawab dengan benar $10-19$ pertanyaan dan kurang jika responden hanya mampu menjawab $<10$ pertanyaan. (Notoatmodjo, 2007 dan Wawan, Dewi, 2011).

Selanjutnya varibel sosial ekonomi adalah pendapatan keluarga dalam satu bulan, diukur dengan skala ordinal: di atas Upah Minimum Propinsi (UMP) $\geq$ Rp. $1.550 .000 / \mathrm{bln}$ dan di bawah UMP < Rp. 1.550.000/bln. (JDIH Prov. Aceh, 2008). Uji validitas dan reabilitas apabila responden tidak mengerti cara pengisian kuesioner maka peneliti menjelaskan cara pengisian.

\section{Hasil}

Karakteristik umum responden yaitu Wanita Usia Subur (WUS) yang sedang berkunjung ke Puskesmas Langsa Lama dan bersedia menjadi responden. Dari hasil penelitan terhadap 62 responden di Puskesmas Langsa Lama, didapatkan hasil sebanyak 41 responden $(66,1 \%)$ merupakan akseptor suntik dan non akseptor suntik sebanyak 21 responden $(33,9 \%)$. Berdasarkan usia didapat hasil sebanyak 32 respoden $(51.6 \%)$ berusia kuisioner dilakukan terhadap 30 reponden di Puskesmas yang sama.

Analisis data dilakukan dengan cara deskriptif dan disajikan dalam bentuk tabek distribusi frekuensi. Etika penelitian ini dengan cara peneliti memperkenalkan diri dan menjelaskan tujuan peneliti, serta memberikan lembar persetujuan untuk diisi oleh calon responden sebelum melakukan penelitian. Setelah lembar persetujuan diisi oleh responden baru diberikan format kuesioner untuk

diisi,

20- 25 tahun dan 30 responden (48.4\%) berusia 26-30 tahun. Analisis hubungan pengetahuan ibu terhadap pemilihan alat kontrasepsi dapat dilihat pada tabel 1.

Tabel1.

Distribusi Frekuensi Pengetahuan, Pendidikan dan Sosial Ekonomi Akseptor Dalam Memilih Alat Kontrasepsi Keluarga Berencana

\begin{tabular}{|c|c|c|c|c|c|c|c|c|c|}
\hline \multirow[t]{3}{*}{ No } & \multirow[t]{3}{*}{ Variable } & \multirow{3}{*}{$\begin{array}{c}\mathrm{N} \\
(100)\end{array}$} & \multicolumn{4}{|c|}{ Akseptor KB } & \multirow{2}{*}{\multicolumn{2}{|c|}{ Total }} & \multirow{3}{*}{$\begin{array}{c}X^{2} \\
\text { (value) }\end{array}$} \\
\hline & & & \multicolumn{2}{|c|}{ Non suntik } & \multicolumn{2}{|c|}{ Suntik } & & & \\
\hline & & & $\mathrm{F}$ & $\%$ & $\mathrm{~F}$ & $\%$ & $\mathrm{~F}$ & $\%$ & \\
\hline \multirow[t]{4}{*}{1} & Pengetahuan & & & & & & & & \multirow{4}{*}{0,004} \\
\hline & a. Baik & 11,3 & 6 & 40,0 & 9 & 60,0 & 15 & 100 & \\
\hline & b. Cukup & 50,0 & 12 & 31,6 & 26 & 68,4 & 38 & 100 & \\
\hline & c. Kurang & 38,7 & 3 & 33,3 & 6 & 66,7 & 9 & 100 & \\
\hline \multirow[t]{4}{*}{2.} & Pendidikan & & & & & & & & \multirow{4}{*}{0,071} \\
\hline & a. Tinggi & 24,2 & 5 & 71,4 & 2 & 28,6 & 7 & 100 & \\
\hline & b. Menengah & 61,3 & 10 & 32,3 & 21 & 67,7 & 31 & 100 & \\
\hline & c. Dasar & 14,5 & 6 & 25,0 & 18 & 75,0 & 24 & 100 & \\
\hline \multirow[t]{3}{*}{3.} & Sosial ekonomi & & & & & & & & \multirow{3}{*}{0,000} \\
\hline & a. Rendah & 54,8 & 21 & 75,0 & 7 & 25.0 & 28 & 100 & \\
\hline & b. Tinggi & 45,2 & 0 & 0,0 & 34 & 100 & 34 & 100 & \\
\hline
\end{tabular}

\section{Sumbr : Data Primer}

Dari tabel 1 dapat diketahui bahwa diantara 38 responden (100\%) yang berpengetahuan cukup mayoritas menggunakan KB suntik yaitu 26 responden $(68,4 \%)$, sedangkan dari 15 responden (100\%) yang berpengetahuan cukup mayoritas ibu menggunakan kontrasepsi suntik yaitu 9 responden $(60,0 \%)$ dan diantara 9 responden $(100 \%)$ dengan pengetahuan kurang, mayoritas responden menggunakan 
kontrasepsi suntik yaitu 6 responden $(66,7 \%)$. Hasil uji beda proporsi dengan Chi-square $\left(\mathrm{X}^{2}\right)$ menunjukkan adanya hubungan antara pemilihan kontrasepsi terhadap pengetahuan ibu di Puskesmas Langsa Lama Kota Langsa $\left(\mathrm{P}_{\text {value }}=<0,004\right)$.

\section{Diskusi}

Penelitian yang dilakukan terhadap 62 responden yang diteliti di Puskesmas Langsa Lama Tahun 2017, mayoritas berpengetahuan cukup yaitu 38 responden $(61,3 \%)$ dan minoritas berpengetahuan kurang yaitu 9 responden $(14,5 \%)$.

Hal ini menunjukan rata-rata responden memiliki pengetahuan cukup yaitu sebanyak $(61,4 \%)$ memilih Suntik sebagai alat kontrasepsi, akseptor memilih kontrasepsi ini dikarenakan akseptor mengetahui dan paham akan kerugian dan keuntungan dari alat kontrasepsi suntik. Peneliti berasumsi Semakin baik pengetahuan seseorang tentang Suntik semakin banyak pula akseptor memilih suntik. Hasil uji beda proporsi dengan Chi - Square $\left(\mathrm{X}^{2}\right)$ menunjukkan adanya hubungan antara pemilihan kontrasepsi terhadap pengetahuan ibu di Puskesmas Langsa Lama Kota langsa $\left(P_{\text {value }}=<0,004\right)$

Hal ini sesuai dengan penelitian Viviroy (2008), Pada variabel pengetahuan dengan perilaku melalui uji Chi-square didapatkan hubungan yang bermakna antara pengetahuan dengan perilaku ibu akseptor KB mengenai kontrasepsi suntik. Hal ini berarti pengetahuan ibu akseptor KB memengaruhi perilakunya dalam memilih kontrasepsi suntik sebagai alat kontrasepsi karena ibu dengan pengetahuan tinggi tentu mempunyai perilaku yang berbeda dengan yang pendidikannya rendah karena ibu yang berpengetahuan tinggi lebih memilih cara penggunaan alat kontrasepsi yang lebih efisien dan praktis.

Pada variabel pengetahuan dengan perilaku melalui uji Chi-square didapatkan hubungan yang bermakna antara pengetahuan dengan perilaku ibu akseptor KB mengenai kontrasepsi suntik. Hal ini berarti pengetahuan ibu akseptor KB memengaruhi perilakunya dalam memilih kontrasepsi suntik sebagai alat kontrasepsi karena ibu dengan pengetahuan tinggi tentu mempunyai perilaku yang berbeda dengan yang pendidikannya rendah karena ibu yang berpengetahuan tinggi lebih memilih cara penggunaan alat kontrasepsi yang lebih efisien dan praktis.
Hal ini juga sesuai dengan penelitian Kundi (2014), pengetahuan tentang KB merupakan salah satu aspek penting ke arah pemahaman tentang berbagai alat/cara kontrasepsi di Kelurahan Sumbersari Kabupaten Jember tahun 2005. Pada penelitian tersebut didapatkan bahwa tingkat pengetahuan PUS tentang KB dan metode kontrasepsi cukup tinggi sebesar 53,5\%.

Kontrasepsi suntik dinilai efektif, pemakaiannya yang praktis, harganya relative murah dan aman (BKKBN, 2017). Hal ini juga sesuai dengan penelitian Karuniawati (2005), dengan judul 'Hubungan antara pengetahuan dan sikap dengan keputusan ibu menggunakan kontrasepsi pil di wilayah Puskesmas Manahan Surakarta'. Penelitian ini menggunakan metode cross sectional dengan pendekatan metode kuantitatif. Hasil penelitian dapat disimpulkan bahwa pengetahuan aseptor dalam keputusan menggunakan kontrasepsi pil memberikan pengaruh. Semakin tinggi nilai pengetahuan maka semakin cepat keputusan ibu dalam menggunakan kontrasepsi pil, walaupun pendidikan tidak berpengaruh.

Pengetahuan ibu yang tinggi akan empat kalinya lebih cepat dalam mengambil keputusan. Hal ini juga sesuai dengan penelitian yang dilakukan oleh Meliati (2005) dalam Kurniawati (2008), dengan judul 'Hubungan pengetahuan aseptor KB tentang kontrasepsi rasional dalam pemilihan metode kontrasepsi rasional dalam pemilihan metode kontrasepsi di desa Bangun Cipto Yogyakarta'. Jenis penelitian analitik non experimen dengan pendekatan cross-sectional, kemudian dianalisis dengan analisis Chi Square. Hasil penelitian menunjukkan terdapat hubungan antara pengetahuan tentang kontrasepsi dengan pemilihan metode kontrasepsi yang signifikan.

Menurut Notoatmojo (2007), pengetahuan adalah merupakan hasil dari tahu dan ini terjadi setelah orang melakukan penginderaan terhadap sesuatu objek tertentu, penginderaan terjadi melalui pasca indera manusia yakni indera pengelihatan, pendengaran, penciuman, rasa dan raba. Sebagian besar pengetahuan manusia diperoleh dari mata dan telinga.

Akseptor yang memilih alat kontrasepsi suntik rata-rata memahami kontrasepsi jenis ini baik dari segi manfaat, 
keunggulan, kerugian maupun pemakaian yang begitu mudah. Dalam hal ini terlihat bahwa semakin baik tingkat pengetahuan akseptor maka semakin baik pula pemahamannya tentang kontrasepsi suntik.

Penelitian yang dilakukan terhadap 62 responden yang diteliti mayoritas berpendidikan menengah yaitu 31 responden $(50,0 \%)$ dan minoritas berpendidikan tinggi yaitu 7 responden $(11,3 \%)$. Hasil uji beda proporsi dengan Chi - Square $\left(\mathrm{X}^{2}\right)$ menunjukkan tidak adanya hubungan antara pemilihan kontrasepsi terhadap pendidikan ibu di Puskesmas Langsa Lama Kota langsa $\left(\mathrm{P}_{\text {value }}=<0,0071\right)$. Hasil penelitian menunjukkan bahwa walaupun pendidikan akseptor rata-rata menengah tapi tetap menggunakan suntik sebagai alat kontrasepsi. Hal ini mungkin karena alat kontrasepsi tersebut digunakan 1 atau 3 bulan sekali dan harganya relatif murah makanya akseptor banyak memilih KB suntik. Hal ini sesuai dengan penelitian Mulbar (2004) dalam Kundi (2014), dampak relatif pemakaian kontrasepsi pil terhadap fertilitas di Sulawesi:

Hal ini sesuai dengan penelitian Syamsiah (2002) tentang 'Peranan dukungan suami dalam pemilihan alat kontrasepsi suntik KB pada peserta KB di Kelurahan Serasan Jaya, Soak Baru dan Balai Agung Kecamatan Sekayu Kabupaten Musi Banyuasin, tahun 2002'. Hasil penelitian menunjukkan alasan responden memilih suntik sebagian besar mengatakan aman $(78,8)$, sedangkan alasan tidak memakai suntik mayoritas mengatakan takut efek samping $(88,23)$. Hasil analisis chi square menunjukkan adanya hubungan antara umur, pendidikan suami, jumlah anak hidup dan dukungan suami dalam memilih alat kontrasepsi. Analisis regresi logistik diperoleh faktor yang paling dominan adalah dukungan suami.

Notoatmodjo (2007), pendidikan kesehatan adalah suatu penerapan konsep pendidikan di dalam bidang kesehatan maka konsep pendidikan kesehatan itu juga proses belajar individu, kelompok dan masyarakat dari tidak tahu termasuk dalam hal memilih pelayanan kesehatan. Peneliti berasumsi bahwa ternyata akseptor yang memilih alat kontrasepsi suntik memiliki pendidikan menengah. Semakin tinggi tingkat pendidikan akseptor semakin baik pula pemahamannya tentang kontrasepsi suntik.
Sedangkan untuk data pengaruh pemilihan kontrasepsi terhadap tingkat sosial ekonomi dari 34 responden (100\%) yang bersosial ekonomi tinggi mayoritas menggunakan $\mathrm{KB}$ suntik yaitu 34 responden (100\%), sedangkan dari 28 responden $(100 \%)$ yang bersosial ekonomi rendah mayoritas ibu menggunakan kontrasepsi suntik yaitu 7 responden $(25,0 \%)$. Hasil uji beda proporsi dengan Chi - Square $\left(\mathrm{X}^{2}\right)$ menunjukkan adanya hubungan antara pemilihan kontrasepsi terhadap sosial ekonomi di Puskesmas Langsa Lama Kota langsa $\left(\mathrm{P}_{\text {value }}=<0,000\right)$. Penelitian yang dilakukan terhadap 62 responden yang diteliti di Puskesmas Langsa Lama, responden memiliki Sosial Ekonomi tinggi yaitu 34 responden $(54,8 \%)$ dan responden yang memiliki Sosial ekonomi rendah yaitu 28 responden $(45,2 \%)$. Hasil uji beda proporsi dengan $\left(\mathrm{X}^{2}\right)$ menunjukkan adanya hubungan antara pemilihan kontrasepsi terhadap sosial ekonomi di Puskesmas Langsa Lama Kota langsa $\left(\mathrm{P}_{\text {value }}=0,000<\right)$. Hasil penelitian menunjukkan akseptor dengan sosial ekonomi tinggi memilih suntik sebagai alat kontrasepsi.

Hal ini tidak sesuai dengan penelitian Radita (2009), tentang 'Faktor-faktor yang memengaruhi pemilihan jenis kontrasepsi yang digunakan pada pasangan usia subur'. Sebagian besar responden memilih non Metode Kontrasepsi Jangka Panjang (MKJP) sebagai jenis kontrasepsi yang digunakan. Faktor tingkat kesejahteraan keluarga, kepemilikan Jamkesmas, tingkat pengetahuan, dukungan pasangan, dan jarak tempat tinggal tidak memiliki hubungan yang bermakna dengan pemilihan jenis kontrasepsi yang digunakan pada PUS. Faktor umur istri, jumlah anak, dan tingkat pendidikan memiliki hubungan yang bermakna dengan pemilihan jenis kontrasepsi yang digunakan pada PUS.

Adapun kelemahan yang peneliti temui dalam penelitian ini adalah kurangnya variable lain yang mungkin dapat memengaruhi hasil penelitian, seperti bagaimana dan darimana informasi mengenai KB suntik yang didapat oleh responden, serta bagaimana peran petugas kesehatan dalam memberikan informasi mengenai KB suntik. Kita ketahui bahwa sampai saat ini belum tersedia satu metode kontrasepsi yang benarbenar $100 \%$ ideal atau sempurna. Pengalaman menunjukkan bahwa saat ini pilihan metode kontrasepsi umumnya masih dalam bentuk 
kafetaria atau informasi umum masyarakat dilingkungannya.

\section{Kesimpulan}

Dalam uji bivariat ditemukan adanya pengaruh yang signifikan pemilihan alat kontrasepsi dengan pengetahuan dan sosial ekonomi akseptor $(\mathrm{p}=$ value $<0,05)$, sedangkan variabel pendidikan tidak memengaruhi akseptor dalam memilih alat kontrasepsi KB. Oleh karenanya sangat diharapkan agar kerja sama petugas kesehatan dalam kegiatan promosi dan penyuluhan kesehatan terutama konseling KB dapat lebih ditingkatkan.

\section{Daftar Pustaka}

BKKBN, 2017. KB Suntik. https://www.bkkbn.go.id/search/kb-suntik Dikutip Tanggal 22 September 2017.

CNN Indonesia, (2017). Pemerintah Galakkan lagi program Keluarga Berencana. Retrieved from https://m.cnnindonesia.com/gayahidup/20170426200152-255-210404/pemerintahgalakkan-lagi-program-keluarga-berencana/

Dinas Kesehatan Kota Langsa. (2012). Penyeliaan fasilitatif pelayanan Keluarga Berencana. Laporan tidak dipublikasikan.

Dinas Kesehatan Kota Langsa. (2016). Profil Kesehatan Kota Langsa Tahun 2015. Retrieved from http://www.depkes.go.id/resources/download/pro fil/PROFIL_KAB_KOTA_2015/1173_Aceh_Kot a_Langsa_2015.pdf

JDIH Prov. Aceh. (2008). Penetapan Upah Minimum Provinsi

Aceh. https://jdih.acehprov.go.id/peraturan-gubernurnomor-95-tahun-2008-tentang-penetapan-upahminimum-provinsi-nanggroe-aceh-darussalam

Karuniawati, O, (2005). Hubungan antara pengetahuan dan sikap dengan keputusan ibu menggunakan kontrasepsi pil di wilayah Puskesmas Manahan Surakarta (Skripsi). Universitas Muhammadiyah Surakarta, Jawa Tengah, Indonesia.

Kundi, A. (2014). Hubungan antara tingkat pengetahuan tentang keluarga berencana (KB) dan metode kontrasepsi dengan kesesuaian pemilihan metode kontrasepsi (Studi pada wanita Pasangan Usia Subur (PUS) di Kelurahan Sumbersari, Kecamatan Sumbersari, Kabupaten Jember, Periode 2004-2005) (Skripsi). Universitas Jember, Jawa Timur, Indonesia.

Kurniawati, Y, 2008. faktor-faktor yang berhubungan dengan sikap ibu dalam pemilihan alat kontrsasepsi suntik Depo Medroksi Progesteron Asetat (DMPA) di RB.Kharisma Husada Kartasura Sukoharjo. Skripsi Fak. Ilmu Kesehatan Univ. Muhamadiyah Surakarta. Surakarta.

Kusumaningrum, Radita (2009) Faktor-Faktor Yang Mempengaruhi Pemilihan Jenis Kontrasepsi Yang Digunakan Pada Pasangan Usia Subur. Undergraduate thesis, Medical Faculty. http://eprints.undip.ac.id/19194/ dikutip tanggal 17 April 2016

Manuaba, I.B.G, (2008). Kapita selekta penatalaksanaan rutin obstetri ginekologi dan $K B$. Jakarta: EGC.

Notoatmodjo, S, 2007. Ilmu kesehatan masyarakat. Jakarta: Rineka Cipta.

Notoatmodjo, S, 2007. Pendidikan Prilaku Kesehatan, Rineka Cipta. Jakarta

Samsiyah, 2002. Pengaruh Peranan Dukungan dalam pemilihan Alat Kontrasepsi pada Peserta KB di Kelurahan Serasan Jaya, Soak Baru dan Balai Agung Kecamatan Sekayu Kabupaten Musi Banyuasin Sumatra Selatan Tahun 2002. www.digilib.ui.ac.id/file?file=pdf/abstrak72168.pdf dikutip tanggal 7 Desember 2015.

Wawan, A dan Dewi, 2011. Teori. \& Pengukuran Pengetahuan, Sikap, Dan Perilaku ManusiaDilengkapi Contoh Kuesioner. Nuha Medika. Jogjakarta. 